were under immunosuppressive therapy and $60 \%$ of them received biological treatment. $20 \%$ of patients had clinical activity data. The average of global VAS was $12(0-100)$ and the average of VAS pain was $0.9(0-100)$. The average of initial PEDSQL 4.0 was $80.7(0-100)$ and the PEDSQL 4.0 at three months was 74.4 . At the end of the workshops, $100 \%$ of parents and patients would recommend other patients to attend it, more than $50 \%$ of patients think that they would be able to go to medical visits without their parents and $90 \%$ of them would take responsibility for their treatments. A $90 \%$ of patients think that workshops have helped to improve their relationship with their rheumatologist and $60 \%$ of them have improved their knowledge about the disease. Regarding to physical activity leves, $30 \%$ of the patients have increased it compared to baseline. More than $50 \%$ of parents have observed a positive attitude change towards the disease after the program.

Conclusions: Transition programs are important for the transfer to be effective throughout the involvement of adolescent, who takes responsibility for his/her disease and also to ensure their psychosocial needs are met. Rheumatologists must be ready to cover these needs with the support of other specialists. Our experience with the program was very positive since most of the patients improved their knowledge about the disease and its autonomy concerning their medical consultations and treatments, being very satisfied with the contents of the workshops.

Disclosure of Interest: None declared

DOI: 10.1136/annrheumdis-2017-eular.6525

\section{AB1190 BEHAVIOR AND TRENDS IN COLOMBIAN PATIENTS WITH RHEUMATIC DISEASES RELATED TO THE TECHNOLOGICAL TOOLS IN CONSULTATION OF RHEUMATOLOGY}

M.C. Latorre $^{1}$, A.M. Ocaña ${ }^{2} .{ }^{1}$ Reumatologia, Country Medical Center;

${ }^{2}$ Electronic Engineering, Octesoft, Bogota, Colombia

Background: In the last decades the internet has changed the way of communication with patients using email, social media and other technological tools, as a complement to the consultation. The development of websites and electronic history are part of these tools that have come to change communication with the patient.

Objectives: To analyze the behavior and trends of Colombian patients with rheumatic diseases related to use electronic tools.

Methods: We analyzed 425 patients between September 2015 and December 2016, who attended to consultation at Country Medical Center. Everyone was provided the website http://www.dra-mconstanzalatorre-reumatologa.com/. This website was developed by Octesoft (http://www.octesoft.com/), company specialized in development website and software. In this website have general information the clinic, access, schedules, glossary, news, medical information and can request online appointment

Results: We included 425 patients with rheumatic diseases, $85.5 \%$ female, with an average age of 52.5 years old. $95 \%$ lived in urban areas. 92\% had internet access. $80 \%$ had smart phone. They were stratified by educational level, finding that $70 \%$ had college level. And by age groups it was found that patients between 30 and 50 years old in $72 \%$ of cases used the electronic way to request the appointment or ask questions. Patients between 18 to 29 years old prefer social media. Patients over 60 years of age preferred to use the telephone. The reasons for using the online appointment were: easy access at any time $84 \%$ tool speed $10 \%$. Difficulty for the use of the telephone at work $2 \%$. Others $4 \%$. When patients communicate via email $90 \%$ of the questions are related to requesting the appointment

During this period the website had 3860 views. With a progressive increase from 60 to 538, with an average of 227, with the highest number of visits between November and December. The patients showed satisfaction with the use of technological tools by $89 \%$.

There is no relationship with the use of technological tools with other factors such as gender, rheumatic disease, other diseases or job.

Conclusions: In this study we find that patients gradually and progressively adopt the use of other tools for communication different from conventional, such as web site or email in the request of their appointments and in the communication with rheumatologist. We found that the main factors for adopting these changes are the group of age, especially between 30 to 50 years old and the level of education, when the level of study is university, tend to use on-line communication. It is important to give different alternatives of communication to patients according to their characteristics.

References:

[1] Bujnowska-Fedak BMC Public Health 2015; 15:194.

[2] González ME, Quesada G, Urrutia I, Gavidia JV. Int J Health Care Quality Assurance. 2006;19(2):146-57.

[3] Khoury,V. Kourilovitch,M. Massardo,L. Clin Rheumatol 2015; 34 (Suppl 1):S45-S49.

Disclosure of Interest: None declared

DOI: 10.1136/annrheumdis-2017-eular.6085

\section{AB1191 ANALYSIS OF FACTORS RELATED TO THE LEARNING OF RHEUMATOLOGY BY TRAINING DOCTORS OF OTHER SPECIALTIES}

M.A. Belmonte-Serrano ${ }^{1}$, P. Tejón-Menendez ${ }^{2}$, J.A. Castellano-Cuesta ${ }^{3}$, N. Fernandez-Llanio ${ }^{3}$, P. Bernabeu ${ }^{4}$, V. Jovaní-Casado ${ }^{5}$, J. Rosas Gomez-Salazar $^{6}$, F. Navarro-Blasco ${ }^{7}$, A. Ybañez-Garcia ${ }^{8}$, A. Lozano-Saez ${ }^{9}$ on behalf of Reumeval working group. ${ }^{1}$ Reumatología; ${ }^{2}$ Hospital General de Castellón, Castellón de la Plana; ${ }^{3}$ Reumatología, Hospital Arnau de Vilanova, Valencia; ${ }^{4}$ Reumatología, Hosp San Juan; ${ }^{5}$ Reumatología, Hosp General; ${ }^{6}$ Reumatología, Hosp Marina Baixa, Alicante; ${ }^{7}$ Reumatología, Hosp General, Elx; ${ }^{8}$ Reumatología, Hosp Peset, Valencia; ${ }^{9}$ Reumatología, Hospital General, Castellón de la Plana, Spain

Background: Many doctors in training of other specialities make a monthly rotation in the rheumatology unit, but usually no formal assessment of the skills and knowledge acquired is performed.

Objectives: To know which factors are related to learning of Rheumatology skills by training doctors (MIR) of other specialties rotating in spanish Rheumatology units.

Methods: An online platform for the evaluation of the knowledge of Rheumatology has been developed (REUMEVAL, see www.reumeval.com). It contains a set (DB) of 300 multiple-choice questions developed by staff rheumatologists on 10 topics of general interest. The set questions passed a Delphi round and $15 \%$ of them were replaced by more appropriate ones.

Each MIR that goes to perform a rotation in a teaching Rheumatology Unit (REU) is offered to participate with two tests of 30 questions randomly extracted from the DB. The first test is done just arriving at REU, assessing the basic knowledge that was obtained in the university. At the end of the rotation in REU, usually 30 days, a second test is performed, assessing the increase of knowledge achieved. Results: As of December 2016, 384 tests were carried out by 216 physicians training in 14 hospitals of the Valencian region in Spain Of these, $166(77 \%)$ completed both tests. $74 \%$ were in training for family medicine (MFC). The mean score of the 1st test was 5.59 (out of 10 points), and the second test was 6.55 points, with an average increase of scorings of $22.4 \%(p<0.001)$. Men showed higher scorings than women in their 1 st test (5.92 vs 5.56 ), but the difference was lost in the 2 nd test (6.79 vs 6.47). Younger residents (ages $20-30$ years) had a 1 st higher score than those aged $30-40$ or $>40$ years (5.8 vs 5.2 vs 5.1 respectively) but were similar in the 2 nd test ( 6.6 Vs 6.3 vs. 6.8). By nationality, Spaniards had higher initial scores than foreigners (5.78 vs $4.91, \mathrm{p}<0.01)$ but there were no differences in the second test (6.55 vs 6.49). For specialties, dermatology, internal medicine and RHB had initial scores higher than MFC (7.3 - 6.1 - 6.3 vs. $5.4)$, but in the second test there were no significant differences.

Conclusions: The level of knowledge in Rheumatology of the residents who start a training rotation in this specialty is moderate, with an average of 5.59 points out of 10 possible. At the end of the rotation their scores increased an average of $22 \%$, which shows a significant improvement but still not very high. Several factors were related to basic knowledge scores but lost significance in the final test, reflecting appropriate improvements in knowledge in all subgroups.

Acknowledgements: To Fundacion Valenciana de Reumatologia and to MSD laboratories for an unrestricted grant.

Disclosure of Interest: None declared

DOI: 10.1136/annrheumdis-2017-eular.4498

\section{AB1192 NATIONAL BAROMETER TO ASSESS THE EMOTIONAL ASPECTS OF PATIENTS WITH RHEUMATOID ARTHRITIS. OPINAR PROJECT}

S. Castañeda Sanz ${ }^{1}$, M.A. Gonzalez-Gay ${ }^{2}$, E.F. Vicente ${ }^{1}$, C. Alegre de Miguel $^{3}$, M. De la Hera ${ }^{4}$, V. Torrente-Segarra ${ }^{5}$, L. Merino-Meléndez ${ }^{6}$, A. Juan-Mas ${ }^{7}$ L. Alcaide ${ }^{8,9}$, A.I. Torralba ${ }^{9}$, J.L. Baquero ${ }^{10} .{ }^{1}$ Rheumatology, Hospital de la Princesa, Madrid; ${ }^{2}$ Rheumatology, H. Marques de Valdecilla, Santander; ${ }^{3}$ Rheumatology, H U Quirón-Dexeus, Barcelona; ${ }^{4}$ Rheumatology, Clínica Mompía, Cantabria; ${ }^{5}$ Rheumatology, H U Hospitalet-Moisès Broggi, Barcelona; ${ }^{6}$ Rheumatology, H General San Pedro, Logroño; ${ }^{7}$ Rheumatology, H U Son Llatzer, Palma de Mallorca; ${ }^{8}$ Rheumatology, ConArtritis; ${ }^{9}$ Rheumatology, Coordinadora Nacional de Artritis; ${ }^{10}$ Scientia Salus, Madrid, Spain

Background: The WHO defines health as the state of physical, psychic and social well-being. In contrast, patients with rheumatoid arthritis (RA) frequently report that treatment is directed mainly at combating physical affection and hardly anything to emotional and social aspects.

Objectives: To assess the emotional impact and degree of satisfaction with the medical care received in the patient with poor prognosis RA.

Methods: National, structured and anonymous survey of 26 questions conducted between March and July 2016. Responses were counted as percentages or as means/medians of the score given on a Likert scale from 1 to 10 (minimum and maximum, respectively). Analyzes were performed using Microsoft 2012: mean $(\mathrm{m})$, standard deviation (SD), median (M), interquartile range (IQR) and statistical significance of differences (Student $t$ test). The study was approved by the National Coordinator ConArtritis and the CEIC of the reference hospital.

Results: The survey was completed by 100 of 122 enrollees, 75 by telephone and 25 via email; 83 women and 17 men, with a mean age of 49.4 years (SD 12.1); from all the Spanish Autonomous Communities. $52 \%$ were considered of poor 